\title{
Forecasting the Success Rate of Reward Based Crowdfunding Projects
}

Ivelin Elenchev

Independent researcher, Bulgaria

ineooo@aubg.bg

Aleksandar Vasilev

Independent researcher, Bulgaria

alvasilev@yahoo.com

The present paper develops three models that help predict the success rate and attainable investment levels of online crowdfunding ventures. This is done by applying standard economic theory and machine learning techniques from computer science to the novel sector of online crowd-based micro-financing. In contrast with previous research in the area, this paper analyses transaction-level data in addition to information about completed crowdfunding projects. This provides a unique perspective in the ways crowd-finance ventures develop. The models reach an average of $83 \%$ accuracy in predicting the outcome of a crowdfunding campaign at any point throughout its duration. These findings prove that a number of product and project specific parameters are indicative of the success of the venture. Subsequently, the paper provides guidance to capital seekers and investors on the basis of these criteria, and allows participants in the crowdfunding marketplace to make more rational decisions.

Key Words: microfinance, entrepreneur finance, crowdfunding

JEL Classification: G17, G19

https://doi.org/10.26493/1854-6935.17.51-77

\section{Introduction}

Crowdfunding is a method of financing business and non-profit endeavours that has a lot in common with micro-finance and crowdsourcing. In some aspects it is similar to the traditional forward contract. Crowdfunding gives entrepreneurs the ability to request capital from a large number of individuals in exchange for interest payments, equity or the delivery of a product at a future date. This is often done through an online platform that grants the project creator the ability to specify the amount of capital he/she is seeking, the duration of the campaign as well as any information about the firm or product that he/she wishes to present to potential 
investors. For other uses of web marketing, e.g., by energy companies, the interested reader is referred to Iovino and Migliaccio (2016; in press).

Giving a clear definition to crowdfunding is somewhat challenging as this emerging field of finance takes several forms. The oldest and most developed one is debt crowdfunding or peer-to-peer lending, which matches lenders directly with borrowers. Another subset of crowdfunding is equity crowdfunding in which investors receive shares of the projects they support. The present paper focuses on the reward-based form of crowdfunding which offers investors the chance to buy a product or receive a reward that will be delivered in the future.

Reward-based crowdfunding can be regarded as an over the counter forward contract between the campaign creator and the buyer or a preorder agreement with constraints set by the capital-seeker and the platform. The paper focuses on the prevalent in practice all-or-nothing scheme of reward-based crowdfunding, in which the funds gathered through the campaign are transferred to the project creator only if the project manages to reach its investment target. Otherwise, the investments are returned to the contributors after the end date of the campaign has passed. Neither the campaign creator nor investors face any charges in case of failure. If the project succeeds a portion of the gathered capital - usually less than $2 \%$ - is taken by the platform in the form of commissions, the rest is immediately transferred to the project creator. All projects that manage to reach or surpass their investment target in the specified duration are regarded as successful. Generally, platforms allow projects to continue receiving investments even after the campaign goal has been reached, unless the project creator has specified that he/she does not wish to do so.

The reward-based form of crowdfunding is a novel financing approach which is largely ignored by standard microeconomic theory and current studies. There is a clear lack of peer-reviewed research regarding the topic as crowdfunding researchers focus predominantly on more traditional peer-to-peer financing methods such as debt and equity crowdfunding in which risk can be easily defined. Through the application of existing theory to the investment dynamics of crowdfunding this paper develops several models that forecast the likelihood of success of crowdfunding ventures. The present paper is unique in crowdfunding literature as it analyses the development of crowdfunding projects throughout their duration as opposed to looking only at already completed ventures.

The information that the models provide serves as an objective mea- 
sure of risk which can be used by entrepreneurs to judge when their product has reached a stage of development that would be sufficient for them to receive the support of investors. Furthermore, the models aid capital seekers in determining how changes in project parameters such as the amount of capital required or the duration of the venture would affect perceived risk. Last but not least, the paper aims to provide entrepreneurs and investors with more precise expectations about the outcome of reward-based microfinance projects and thus allow them to make the optimal financing decision.

In the introductory section of the paper we will outline background information such as research goals and an overview of existing literature. This is followed by a section on data gathering and analysis which describes how information about crowdfunding campaigns was collected and how the factors affecting project success are evaluated. Subsequently, these factors are used in the creation of three distinct models forecasting crowdfunding success. Finally, the paper gives recommendations to capital-seekers and investors on the basis of the robustness of each model.

\section{CROWDFUNDING RESEARCH MOTIVATION}

Crowdfunding has some considerable weaknesses when compared with traditional finance, which include lacking or ineffective legislation, poor fraud control, reputation damages due to failed campaigns - all of them driven primarily by the lack of public information and understanding of the topic. However, the field is worth examining due to a number of factors, which according to the phenomenal growth of crowdfunding in recent years heavily outweigh the dangers and disadvantages. The unique opportunity for diversification that crowdfunding provides offers investors desirable outcomes at a low risk. The spread out campaign risk is allocated among a large number of buyers with similarly sized contributions. This allows the successful development of projects which would have been rejected by banks and venture capitalists.

Furthermore, the crowdfunding financing method allows for a lot of flexibility for both investors and project creators. For example crowdfunding platforms help producers in adapting to the underlying market demand at the early stages of production. They provide a market testing mechanism - the crowdfunding venture itself - that is more representative of actual market demand and often cheaper than a general consumer survey. Additionally, the all-or-nothing rule of crowdfunding enforced by the minimum funding threshold serves as a guarantee to consumers 
TABLE 1 Crowdfunding Growth Forecast by The World Bank

\begin{tabular}{lrrrrrrr}
\hline Year & 2009 & 2010 & 2011 & 2012 & 2013 & 2014 & 2015 \\
\hline Volume & 0.53 & 0.85 & 1.47 & 2.81 & 6.12 & 16.23 & 34.4 \\
\hline
\end{tabular}

NOTES In billion USD. Adapted from The World Bank (2013).

that the venture will be pursued only if the demand is met. This ensures consumers that they will not receive a lesser product in the event of inadequate funding. Furthermore, the active participation of consumers allows producers to determine which product features are desirable by consumers and ultimately enables investors to shape the final product through project feedback.

Platforms can be utilized to demonstrate consumer demand like in the case of Pebble, the first smart watch, which was initially rejected by venture capitalists. After quickly reaching and even surpassing its funding goal on the crowdfunding platform Kickstarter the product managed to attract a large amount of vc capital. Similarly, unsuccessful campaigns give their creators reliable information about the demand for their product at a very low cost. Furthermore, crowdfunding is sometimes used for marketing purposes. It allowed the creators of the Ouya video game platform to attract the attention of game developers before the product was released. The success of the campaign generated a lot of media coverage, which allowed the founders to draw more venture capital.

The rapid growth that crowdfunding has experienced in recent years certainly cannot be ignored. As presented in table 1 the total yearly funding volume of crowdfunding projects has expanded over 60 times from 2009 to 2015 reaching over $\$ 34$ billion. A recent report of The World Bank (2013) predicts that crowdfunding campaigns will reach $\$ 98$ billion by 2025 . The same report states that the industry is likely to surpass venture capital investments as early as 2018. This geometric growth rate is distributed among several industries and encompasses projects of widely varying size. A large number of local projects seek small amounts of capital. These ventures usually take the form of cultural events that do not generate revenue or small local businesses. These campaigns often have capital goals of less than $\$ 3000$ and are financed predominantly by regional investors. However, there is an increasing interest from entrepreneurs looking for an alternative to venture capital and traditional finance. The control, flexibility, low transaction costs and speed that crowdfunding provides to entrepreneurs and investors has resulted in 
a substantial number of large undertakings like the first commercially available $3 \mathrm{D}$ printer, the first virtual reality set, numerous music albums, movies, and $\mathrm{TV}$ shows.

\section{RESEARCH GOALS}

Although crowdfunding receives a lot of media coverage there is a lack of research and adequate regulation focusing on the subject. This is especially true when discussing the reward based form of crowdfunding which unlike debt and equity based crowdfunding rarely benefits from existing government policies. In many countries contributions to rewardbased crowdfunding campaigns are regarded as donations and project creators are not held responsible for their actions after their campaign has been successfully funded. This lack of government interest is in part due to the public belief that reward-based crowdfunding is wild, unpredictable and driven predominantly by fads. The unclear to the public mechanisms through which crowd-based microfinance functions leave the impression that the success of such projects is a matter of random chance. The current lack of information and clear understanding of risk in crowdfunding is damaging for all parties involved as entrepreneurs have to resort to less efficient financing opportunities and contributors are left unaware of the hazards associated with crowdfunding campaigns.

The goal of this paper is to show that consistent dynamics underlie the majority of crowdfunding ventures. This makes their development and eventual outcome predictable at a very early stage, which means that with the help of adequate technology both project creators and supporters could react accordingly. This greater understanding of the evolution of each project would result in a financing mechanism more widely available and more flexible than any form of traditional finance.

\section{LITERATURE REVIEW}

There has been little published peer-reviewed work on the topic of crowdfunding. Initially, the scientific discussion around crowdfunding revolved around the legal aspects of this novel financing mechanism. Subsequently a number of empirical studies dating as early as 2010 analysed market data and investor questionnaires and built the first economic frameworks for understanding crowdfunding. This section will provide a brief overview of the most significant studies relevant to this paper.

First, empirical studies in the capital-seeking category are mainly concerned with the factors leading to campaign success, the legal restric- 
tions of crowdfunding and the motivation of entrepreneurs for choosing this financing option. Belleflamme and Schwienbachner (2011) performed interviews with project creators in order to identify the main reasons for choosing crowdfunding instead of traditional sources of capital. The prompt collection of funds was pointed out as the main objective. Other motives included attracting public attention and testing market demand for the product or service. In similarly structured interviews Hemer (2011) identified another significant reason why entrepreneurs preferred crowdfunding - the opportunity to obtain financing at early stages of product development.

Belleflamme, Omrani, and Peitz (2015) explore the factors driving crowdfunding project success. He identifies that projects with a social cause or non-profit oriented structure have a higher probability of success. According to his research investors perceive non-profit organizations as more credible than small businesses. Mollick (2013) analyses transaction data from a popular crowdfunding platform and concludes that the probability of project success decreases as the project capital target or project duration increases. In addition, Mollick (2014) finds a relationship between the size of a project creator's public social following and the probability of project success. Agrawal, Catalini, and Goldfarb (2011) analysed a market of musicians seeking capital through crowdfunding to understand whether crowdfunding exhibits location constraints similar to venture capital fundraising. His findings suggest that this is indeed the case, although to a lesser extent compared to angel investing and venture capital funding. Burtch, Ghose, and Wattal (2013) examined how timing has affected 100 similar crowdfunding campaigns, finding that projects created on week days exhibit a slightly higher chance of success. Cultural, local and emotional biases seem to be the causes of this relationship, as discussed by Lin, Prabhala, and Viswanathan (2009), Viswanathan and Prabhala (2013) and Burtch, Ghose, and Wattal (2013).

Next, understanding the way investors analyse crowdfunding campaigns is vital to building a model that accurately represents the dynamics of crowdfunding projects. Allison et al. (2014) and Lin, Boh, and Goh (2014) both reach the conclusion that capital providers are not motivated only by financial rewards. Interviews with supporters of crowdfunding campaigns indicate that their investment decisions are in part driven by the interaction with other likeminded individuals due to the close relationship that crowdfunding projects build between creators and supporters. Others state that a general interest in the category of the product fuels 
their decision to support projects for the sake of innovation. These findings were confirmed by Gerber, Hui, and Kuo (2012) who also found that a large share of project supporters desire to be able to interact with the project through social media. Several studies Everett (2010), Freedman and Jin (2014) and Zvilichovsky, Inbar, and Barzilay (2013) discover that larger social networks increase the probability of funding. Herzenstein and Andrews (2008) and Dholakia (2011) examine the degree to which investors mimic their peers and conclude that the herding investment behaviour reduces default rates of peer-to-peer loans. Kuppuswamy and Bayus (2013) find evidence of herding behaviour in reward-based crowdfunding - according to them the herding behaviour is due to payoff externalities as backers tend to support projects closer to reaching their capital goal due to the higher probability of project success.

Studies of investment timing show consistent signalling behaviour that encourages other supporters Koning and Model (2013). Qui (2013) found that blog posts and media coverage in general is positively correlated with project success. Kim and Viswanathan (2013) focused on crowdfunding in the market for mobile applications and found that early endorsement by industry experts increases the likelihood of project success. Hildebrand et al. (2013) shows that endorsements by others are seen as more credible if they are linked with investments, however increased publicity by word-of-mouth also proves to be beneficial to a lesser extent. According to Mollick (2014), investors rely on quality signals similar to those used by venture capitalists such as previous success of the entrepreneur, team quality and product development stage.

Crowdfunding platforms facilitate the matching between entrepreneurs and investors. They are communication, information and interaction portals that determine many of the factors influencing project success. According to Elsner (2013) as well as Haas, Blohm, and Leimeister (2014) the role of the platform is crucial in alleviating information asymmetry and deterring fraud. Ordanini et al. (2011) outlines the business models that the major platforms employ and shows the measures through which they facilitate the building of trust between creators and supporters. Wash and Solomon (2014) analyse whether the all-or-nothing funding model is optimal for all campaigns and conclude that investors tend to contribute higher amounts and at a higher rate in such projects. The researchers recommend the all-or-nothing approach to platforms targeting high risk projects that are at an early stage of development.

Chen, Ghosh, and Lambert (2014) researched whether employing the 
TABLE 2 Number of Analysed Crowdfunding Projects

\begin{tabular}{llr}
\hline Platform & Date range & Number of projects \\
\hline Kickstarter & $05 / 2009-12 / 2016$ & 422,392 \\
Indiegogo & $04 / 2010-12 / 2016$ & 247,820 \\
FundRazer & $10 / 2011-12 / 2016$ & 114,952 \\
RocketHub & $04 / 2010-12 / 2016$ & 45,640 \\
\hline
\end{tabular}

auction model in order to fund crowdfunding projects would result in a more efficient market by analysing recorded transactions on the platform Prosper.com. His research indicates that the auction model does not generate outcomes in the best interest of capital seekers. The increased level of competition in crowdfunding platforms was analyses by Maeschle (2012). Her findings suggest that with the surge of new investment platforms capital providers tend to prefer more open platforms that publish business information about the projects such as firm size, ownership structure, location and balance sheet data.

All these papers offer valuable information, but few research projects to date have provided large-scale insight on the empirical dynamics of crowdfunding. The majority of existing studies have been aimed at campaign investors, not project creators. Since crowdfunding is a new financing method it could potentially be disruptive to traditional finance. There are several areas that should be researched further before we can truly understand what can be achieved through crowdfunding. First, we must find out if the successes and failures of crowdfunding projects are driven by similar underlying dynamic as Venture Capitalist campaigns, or other known financing schemes. Second, since crowdfunding is less dependent on geographic location in comparison to traditional finance we must understand the role, if any, that location has in successful campaigns. This paper attempts to build upon the existing research in these two areas.

\section{Discussion of Data: Some Stylized Facts}

The data used in the development and analysis of the models that this paper builds was gathered from four global online crowdfunding platforms, namely Kickstarter, Indiegogo, Rockethub and Fundrazer. A total of 830,804 crowdfunding ventures were analysed. Table 2 provides a breakdown by platform of the projects used in the analysis.

The data features information about both successful and failed projects. The development of each campaign is represented by a time series of ob- 
servations taken at equal intervals throughout the duration of the campaign. Each observation contains information about the amount of capital invested at that period and the number of investors. Additionally campaign parameters such as category, location, description and data about the campaign creator are taken from crowdfunding platforms and used in two of the models. Investor location was determined using data publicly available in platform user profiles.

Campaign characteristics of all completed Kickstarter projects were analysed and compared to determine their impact on project success. The conclusions that they reach become the framework on top of which our models are built. The following variables were used in the analysis:

- Project goal: The amount founders desire to raise through crowdfunding.

- Investors: The number of investors in the project.

- Avg. Investment: The average contribution amount.

- Updates: Capital seekers are encouraged to post progress information, called updates. These events represent efforts by founders to reach out to current and potential investors, and to inform interested backers about the developments in the project.

- Comments: Investors can post questions and comments in the discussion sections of active and inactive campaigns.

- Duration: The number of days during which a project accepts investments. Kickstarter allows this period to be anywhere between 30 and 60 days.

The coefficients associated with the significance of each campaign variable are listed in table 3 . The examination of campaign variables suggests that the leading positive factors for success in finished projects are the number of campaign updates and the average contribution. The leading negative factors for successful projects are duration and the total goal.

Table 4 shows the average value for each of the parameters in all projects as well as the same measurement for successful projects and campaigns in seven of the most popular product categories. This initial analysis suggests that on average successful projects had a goal twice smaller than the global mean. Additionally, the creators of successful projects were twice as active in terms of campaign updates as the average. There seems to be a big difference in the levels of activity of campaign creators between categories with design and technology projects performing well above the mean. The mean goal and contribution (pledge/backer) also 
TABLE 3 Crowdfunding Success Factors

\begin{tabular}{lrrrrrr}
\hline & $(1)$ & $(2)$ & $(3)$ & $(4)$ & $(5)$ & $(6)$ \\
\hline (1) Goal & -0.16 & & & & & \\
(2) Investors & 0.13 & -0.01 & & & & \\
(3) Avg. Investment & 0.19 & 0.12 & 0.02 & & & \\
(4) Updates & 0.45 & 0.03 & 0.16 & 0.09 & & \\
(5) Comments & 0.05 & 0.13 & 0.56 & 0.02 & 0.11 & \\
(6) Duration & -0.15 & 0.07 & -0.03 & 0.02 & 0.03 & 0.01 \\
\hline
\end{tabular}

TABLE 4 Crowdfunding Factor Averages

\begin{tabular}{lrrrrrrrr}
\hline Variable & $(1)$ & $(2)$ & $(3)$ & $(4)$ & $(4)$ & $(5)$ & $(6)$ & $(7)$ \\
\hline Successful & 0.486 & 1 & 0.485 & 0.391 & 0.455 & 0.466 & 0.53 & 0.62 \\
Avg. Funded \% & 0.762 & 1.524 & 1.12 & 0.66 & 0.789 & 0.553 & 0.611 & 0.823 \\
Goal & 12504 & 7462 & 13071 & 6974 & 11532 & 4395 & 7530 & 8347 \\
Investors & 70.3 & 132.5 & 167.3 & 45.2 & 192.2 & 64.5 & 66.1 & 53.5 \\
Updates & 3.99 & 6.42 & 5.12 & 2.11 & 5.31 & 3.12 & 3.83 & 3.68 \\
Comments & 8.53 & 17.2 & 21.34 & 3.13 & 4.56 & 2.74 & 5.23 & 3.12 \\
Duration (days) & 39.324 & 37.442 & 38.12 & 40.56 & 37.52 & 37.38 & 38.13 & 38.72 \\
\hline
\end{tabular}

varies heavily with categories featuring higher campaign goals receiving larger contributions. Ultimately, campaign category seems to be an important success factor.

It is important to note that this initial analysis was performed on data of completed projects, so the relation of all aforementioned variables to project funding dynamics is not made clear. Furthermore, data about comments and updates does not include the time of each action, meaning that they include actions performed after the project had finished. Evidence suggests that after project completion discussion in the form of comments and founder feedback are rare in unsuccessful project. Projects that have successfully reached their target are often actively monitored by those who have invested in the project and are still waiting to receive their reward. Such projects become a centre for discussion regarding shipping and product feedback. This heavily skews the number of comments and updates towards successful projects, thus the data about them in the initial regression should be taken with a grain of salt.

The success of traditional start-ups is often highly influenced by their location due to positive externalities such as spillovers from successful 


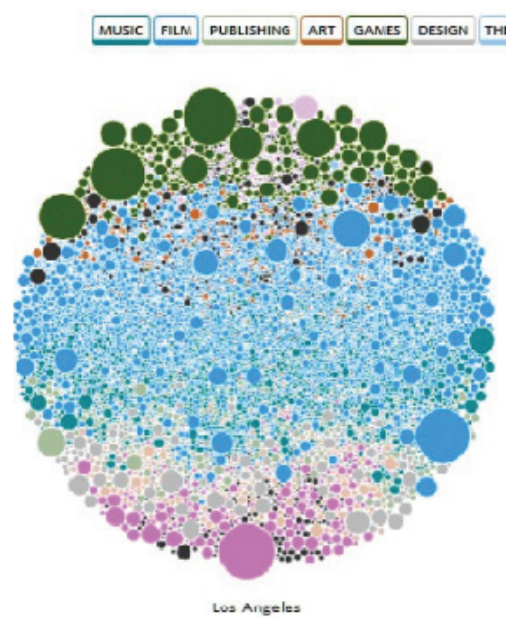

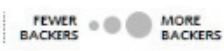

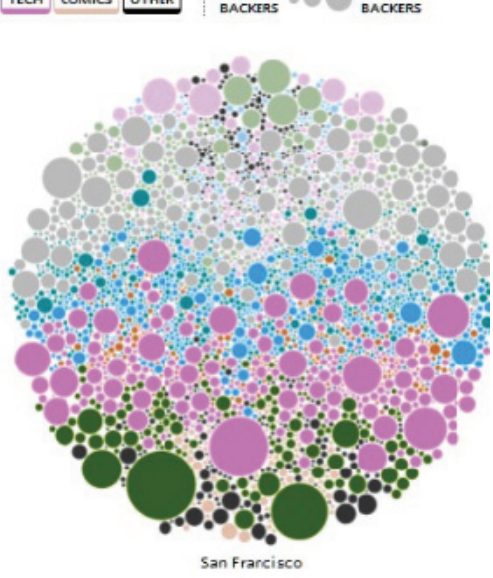

FIGURE 1 Project Distribution by City

projects, industrial clustering and lower hiring costs. In previous examinations by Agrawal, Catalini, and Goldfarb (2011) have shown that crowdfunding is not as dependent on location as venture capitalist projects, however an analysis of campaign location proves that it is an important factor that should not be ignored.

The geographical distribution of projects is uneven. Some regions have a disproportional number of projects in a specific category. Examples include Nashville which has a high concentration of successful music campaigns, Los Angeles which is dominated by film and San Francisco and San Jose which lead the technology and videogame categories. A visualization of the distribution of successful projects shown in figure 1 and figure 2 suggests that in some instances regional trends are very heavy. In particular, more than half of all fully funded projects in the areas of Nashville, Los Angelis, San Francisco and San Jose are in the categories that have traditionally been represented in local businesses. The established local culture and active communities lead to more rapid funding dynamics in projects that fall in these locally dominant categories. This effect is boosted by local-first features in many crowdfunding platforms that feature currently active projects to local investors.

Local and distant investors are different as shown in table 5. Local investors are more likely to invest before the ratio of capital gathered over the capital goal reaches $30 \%$ rather than later. In contrast, distant investors contribute more heavily at the later stages of the campaign when more 
TABLE 5 Crowdfunding Location Breakdown

\begin{tabular}{lrrr}
\hline Distance & Avg. investment & Total investment & \% of total investment \\
\hline Local (under 50 km) & 196 & 228,490 & $13.5 \%$ \\
Distant (over 50 km) & 74 & $1,313,060$ & $77.2 \%$ \\
\hline
\end{tabular}

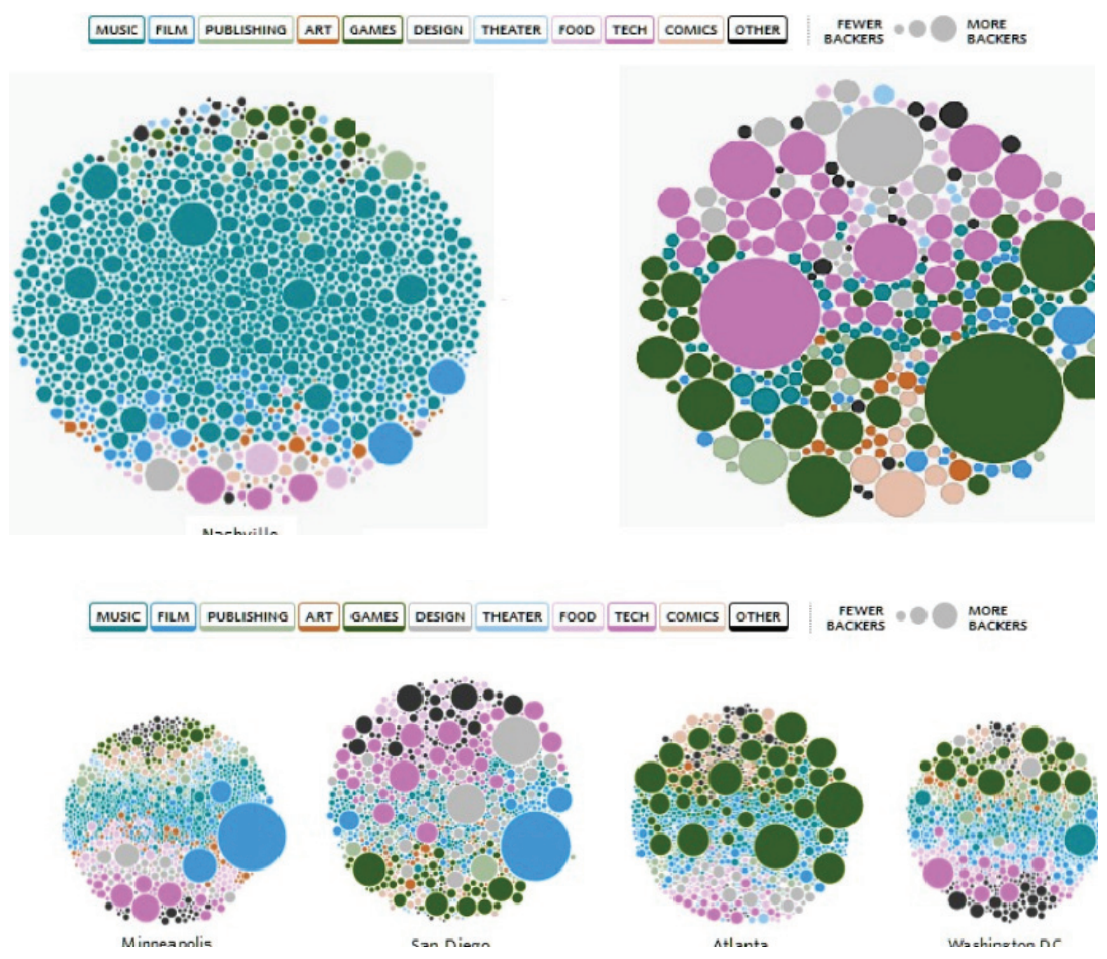

FIGURE 2 Project Distribution by City

than $30 \%$ of the required capital is collected. Additionally, although the total contribution of local investors towards successful projects is much smaller than that of distant investors their average investment is up to 4 times bigger.

There exists a clear relationship between distance, the likelihood to invest and the mean investment. The relation between distance and investment is displayed in table 6 . This makes sense for projects aimed only at the local community, however the same is true for online products made available to the whole world. This is likely due to friend and family connections which are more likely to develop locally. Data from a 
TABLE 6 Crowdfunding Detailed Location Breakdown

\begin{tabular}{lrrr}
\hline Distance & Avg. investment & Total investment & \% of total investment \\
\hline $0-5 \mathrm{~km}$ & 255.76 & 48,850 & $2.9 \%$ \\
$5-50 \mathrm{~km}$ & 184.62 & 179,640 & $10.6 \%$ \\
$50-500 \mathrm{~km}$ & 67.67 & 297,970 & $17.5 \%$ \\
$500-3000 \mathrm{~km}$ & 79.56 & 336,680 & $19.8 \%$ \\
$>3000 \mathrm{~km}$ & 75.15 & 678,410 & $39.9 \%$ \\
\hline
\end{tabular}

TABLE 7 Crowdfunding Relationship Breakdown According to Data from Cumming and Johan (2009)

\begin{tabular}{lrr}
\hline Relation & First \$500 & First 4 weeks \\
\hline Friends \& Family & $34 \%$ & $37 \%$ \\
Not Friends \& Family & $66 \%$ & $63 \%$ \\
\hline
\end{tabular}

survey performed by the crowdfunding platform Kickstarter asked campaign contributors about the reasons why they supported the project. The results showed that friends and family are more likely to contribute at the start of the campaign as shown in table 7. This affirms our findings that the share of the contributions of friends and family falls as the campaign approaches its goal. Moreover, when successful and unsuccessful projects are compared an abnormal percent of the contributions towards unsuccessfully funded campaigns came from friends and family members. However, due to data constraints, it is unclear whether both distance and personal connections are factors weighted by contributors before they support a crowdfunding campaign. Even if distance has no direct relationship on the likelihood investment it seems to be a good predictor of early contributions.

Data collected from several crowdfunding platforms suggests that as the share of gathered capital over the required capital threshold increases the success rate of the project increases non-linearly. This becomes evident from table 8 which shows the final share of collected capital over the capital target for a large number of campaigns with varying capital thresholds. The data shows that a disproportionately large share of the projects are either successfully funded, reaching at least $100 \%$ of their goal, or a relatively small portion of the total threshold

is achieved. Looking even further into the initial 20\% supports these observations as shown in table 9. Furthermore, projects that fail, do so 
TAB LE 8 Crowdfunding Breakdown by Funding Percentage

\begin{tabular}{lrrrrrr}
\hline \% funds raised & $0-19$ & $20-39$ & $40-59$ & $60-79$ & $80-99$ & 100 \\
\hline \% of projects & 55 & 6 & 2.5 & 0.9 & 0.05 & 36 \\
\hline
\end{tabular}

TA b Le 9 Crowdfunding Detailed Breakdown by Funding Percentage

\begin{tabular}{lrrrrr}
\hline$\%$ funds raised & $0-3$ & $4-7$ & $8-11$ & $12-15$ & $16-20$ \\
\hline$\%$ of projects & 62 & 24 & 9 & 3 & 2 \\
\hline
\end{tabular}
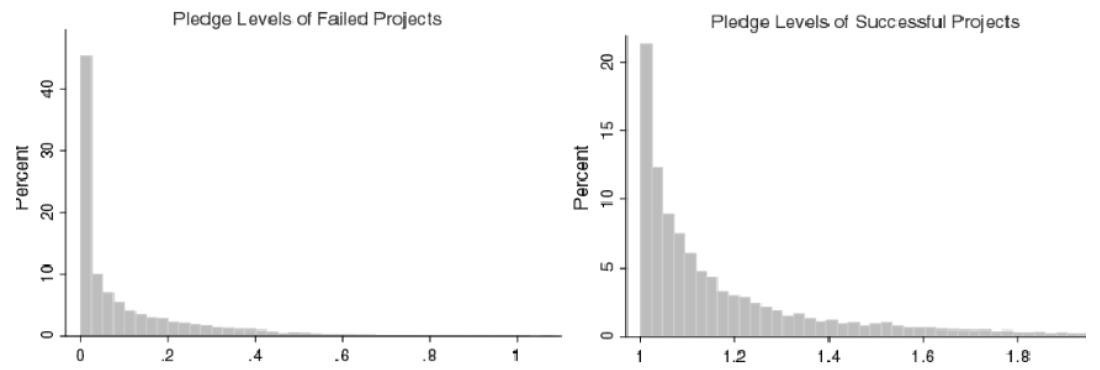

FIgURE 3 Project Distribution by Funding Percentage

by large margins and those who succeed end up with a little over $100 \%$ of their target. This is even more evident in the comparison between successful and failed projects in figure 3 .

This could be the outcome of herd behaviour that results in an increased likelihood to contribute towards projects that are closer to their goal. However, another viable explanation is that the likelihood to invest does not change significantly and founders whose projects succeed have reached a larger audience. Transactional data discussed in the following section sheds more light on this issue. In our analysis of temporal project dynamics we normalize the capital target and the duration of the campaign to 1 . Thus in a project with a capital target of $\$ 500$, an investment of $\$ 100$ made during the halfway mark of the campaign is represented by an investment of size $0.2 \mathrm{k}$ at time period $0.5 \mathrm{t}$.

Figure 4 displays a histogram of the normalized contributions. Each bar stands for the number of contributions received in that period. It is apparent that a large number of contributions are made in the first $10 \%$ of project duration. On average about a quarter of all funds are received in this initial period. The final $10 \%$ of project duration also exhibit a spike in investor activity, with over 50\% more contributions per period than the middle point of the project. 


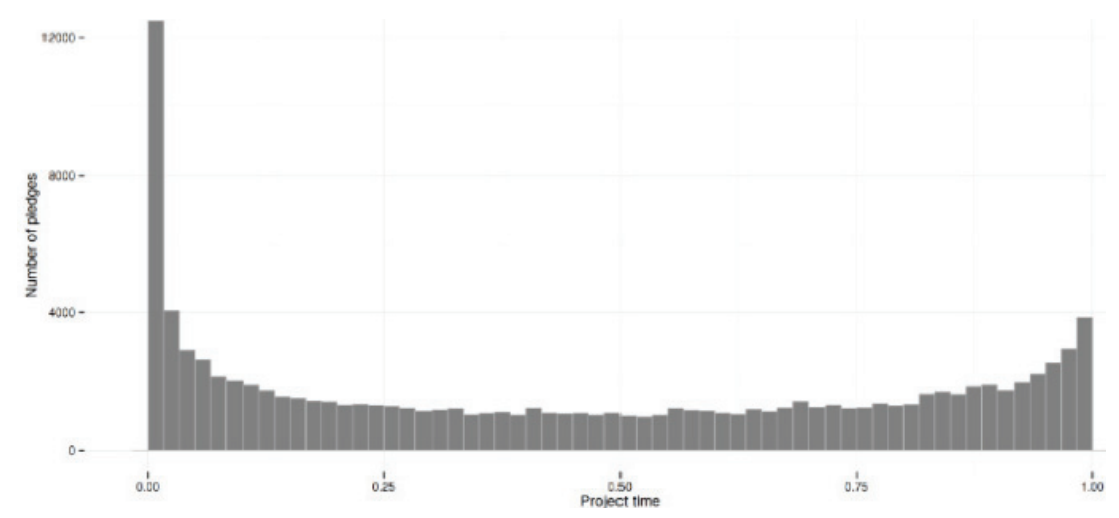

FIGURE 4 Distribution of Pledges over the Normalized Funding Duration

To further examine the dynamics of crowdfunding campaigns, we separate them in two groups depending on the normalized capital ratio that has been reached in the middle of the campaign. The lifespan of projects whose capital ratio is less than 0.5 at the middle of the campaign duration - meaning that the projects have not reached their targets yet - is shown in figure 5. The projects in figure 5 are further separated in two categories. Projects in category A do not manage to reach their capital requirements until the end of the campaign and those in category B do. The data shows a similar distribution of capital ratios in both categories, however projects in category $B$ experience an increase in the rate of contributions after the middle point of campaign duration. This increase becomes more extreme in the final stages of projects in category B, whereas for projects in group A the increase in investments is similar to the one in the initial stages of the campaign.

Figure 6 separates the initially successful projects in three groups group A consists of the projects that did not reach their target, B consists of projects that reached their target and had a capital ratio of less than 1 at the middle of the campaign and group $\mathrm{C}$ is made of all projects that had already reached their capital requirements at the middle of project duration. It is interesting to note that few projects fall in category A as the majority of campaigns that reach $50 \%$ of their capital are usually successful in receiving their full required investments. The low number of observations in group A shows that projects in this group receive investments at a slower rate than they did in the first half of project duration. Campaigns in group B experience almost linear growth. There is an increase in the rate of investments at the last $10 \%$ of project duration but 


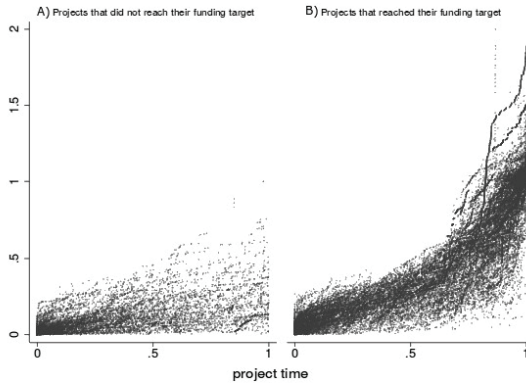

FIGURE 5 Funding Ratio of Initially Unsuccessful Projects

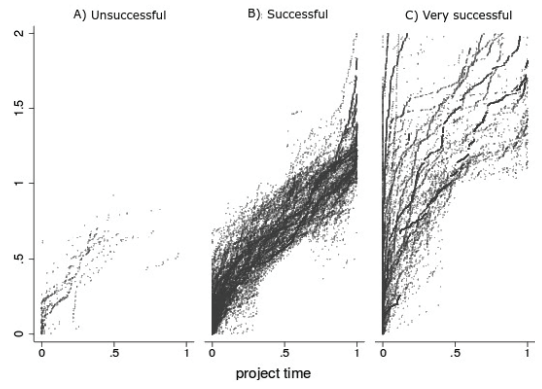

FIGURE 6 Funding Ratio of Initially Successful Projects

this increase is much milder than the one experienced by the initially unsuccessful projects in figure 5. Projects in group $\mathrm{C}$ have little in common - some continue their exponential growth while others do not receive any investments after the middle of the capital requirement has been reached. These observations tell us that the last $10 \%$ of campaign duration are extremely important for projects that do not manage to receive more than half of their capital requirement until the middle of the project duration. For initially successful projects, sustaining the rate of investments is enough to assure success. As shown in figures 5 and 6 a large number of successful projects continue to collect investments after the capital requirement has been reached. On average $16.4 \%$ of all investments are made towards projects that have already reached their goal.

Figure 7 breaks down the findings displayed in figure 4 by project outcome. It takes into account whether the investment was made towards an already successful project, a project that has not reached its goal yet but will do so eventually or a project that will fail.

Figure 8 shows the ratio of investments as a share of all investments in the period to give more insight into the relation of contributions. Campaigns that did not secure enough investments account for a large share of the contributions in the first periods. As time advances the investments towards them virtually disappear. One possible explanation is that investors are able to determine that the project will not be successful, however it is also possible that the effect is due to decreased public attention towards these ventures.

More surprising is the observation that an increasing number of investments in the last periods are made towards projects that have already reached their goal. The number of contributions towards campaigns that 


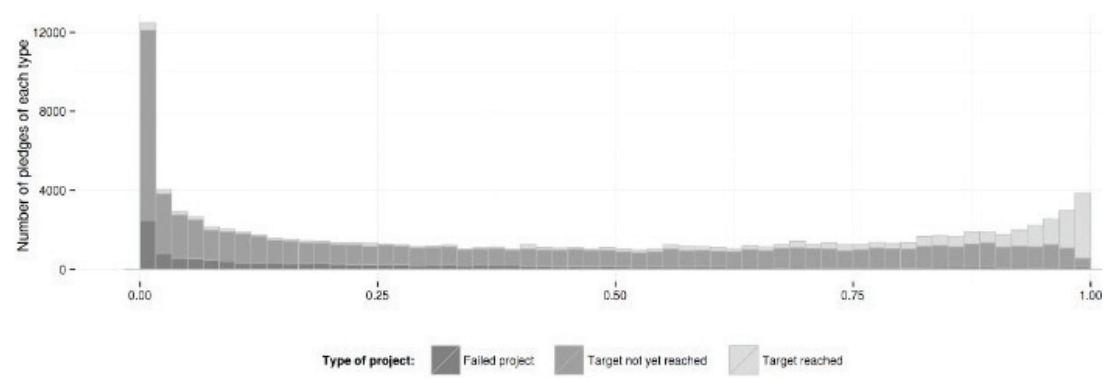

FIGURE 7 Project Investments over Time Breakdown by Project Outcome

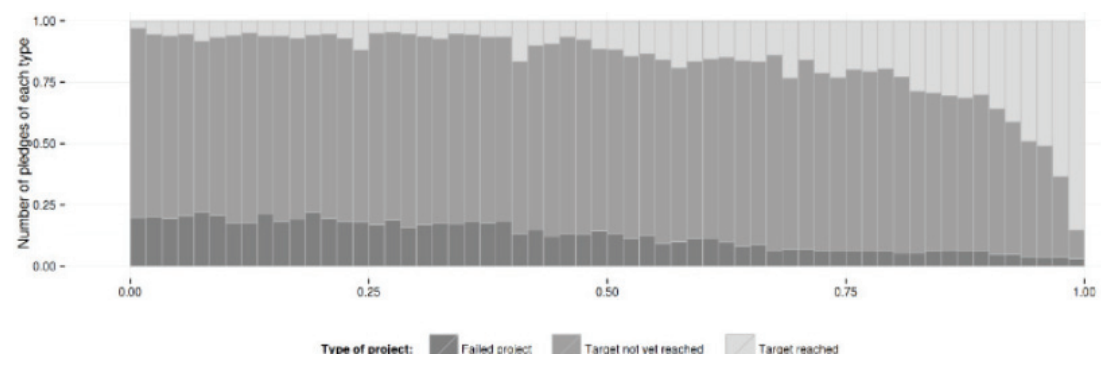

FIGURE 8 Relative Project Investments over Time Breakdown by Project Outcome

haven't reached their targets stays relatively constant which suggests that there is no sudden rush to invest in order to assure project success. However, it is important to understand that the majority of contributions towards projects that are not yet successful in the final periods of figure 7 come from the projects in figure 5 category B. In other words, although the number of contributions stays relatively flat the number of projects that receive these contributions decreases as more and more campaigns reach success as shown in figure 5. Thus there is indeed a rush to invest in projects that are close to reaching success in the final stages of project duration.

Investors are well aware that not all crowdfunding campaigns succeed. According to questionnaires filled by buyers, they take a number of campaign characteristics into account before contributing. Attributes such as team size and experience, the feasibility of the product, its current development stage and the time to product completion are some of the important qualities which buyers watch for. Unsurprisingly, these are to a large extent the characteristics which venture capitalists consider when discounting their expected future returns. Table 1o shows the average discount factor as a function of the stage of development of the product. 
TABLE 10 Venture Capitalist Discount Factors

\begin{tabular}{lrrrrr}
\hline$\%$ development stage & Seed & Angel & Series A & Series B & Bridge \\
\hline \% discount factor & $80-100 \%$ & $50-70 \%$ & $40-60 \%$ & $30-50 \%$ & $25-35 \%$ \\
\hline
\end{tabular}

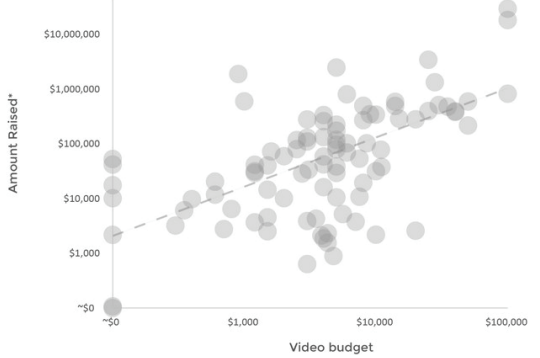

FIGURE 9 Project Breakdown by Video Budget

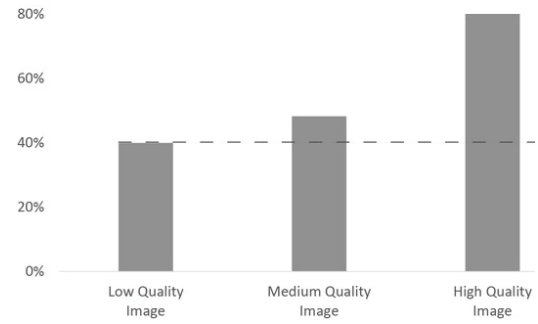

FIGURE 10 Project Breakdown by Video Image Quality

Crowdfunding platforms often encourage campaign creators to satisfy these quality signals when creating new campaigns. For example, Kicksarter heavily promotes the use of videos in addition to project description. Similarly, regular project updates and prompt response to user comments are another signal of quality.

Other campaign signals are often associated with low quality as shown in table 3 and table 4 . Contributors are wary of campaigns with too ambitious goals as their likelihood of success is often small. Even though the all-or-nothing rule assures investors that they will receive their money back if the project fails investors still have to wait until the end of the campaign to get their money back. Naturally, this effect is stronger in projects with longer duration, which as table 3 shows makes campaign duration a negative factor for reaching the desired amount of capital.

These observations help us understand how investors perceive crowdfunding project risk, however an obvious issue in the modelling of risk is that variables such as product quality, team experience and professionalism are open to interpretation. They are hard to analyse for the volumes of data that the present paper considers. Instead we have used data about presentational videos that capital-seekers use to demonstrate their goal and progress. Survey results of project founders and investors reveal that the production cost of videos is directly related to the total goal. Projects seeking up to $\$ 25 \mathrm{k}$ spend less than $\$ 3 \mathrm{k}$ on their video, while projects in the vicinity of $\$ 100 \mathrm{k}$ spend near $\$ 6 \mathrm{k}$ for their project video. Most campaigns 
looking for sums larger than $\$ 1 \mathrm{~m}$ spend upwards of $\$ 2 \mathrm{ok}$. This relation is shown in figure 10.

\section{Models}

Combining the observation from the crowdfunding data we build three distinct models forecasting the success rate of crowdfunding campaigns during any stage of their development. Model A relies on several of the major data relations that we observed - the increased likelihood of local investors to contribute early on, the abnormal concentration of project final funding level near the $0 \%$ and $100 \%$ financing levels, the increased likelihood to invest during the first and last $10 \%$ of project duration and the risk aversion of investors. These characteristics are combined in a unifying model that accounts for investors learning from project investment dynamics in previous periods to predict the total sum of investments gathered after the project ends.

In contrast, Model B performs statistical classification of projects based on all previously discussed data observations using Naive Bayes and Random Forest approaches. Note that while model A predicts total capital model B can only be used to distinguish whether the project was successful in raising the required capital.

Finally, Model C relies only on the category and the funding dynamics of each project to produce a project investment curve. Afterwards the curve is compared to that of already finished projects and using least squares the $N$ most similar projects in terms of funding dynamics are selected. A simple average of the outcomes of these $N$ campaigns is used to predict the end state of the project in question. Similarly to Model B, this approach can only be reliably used to predict whether the campaign is successful.

\section{MODEL VARIABLES}

- Campaign goal: $K^{\star}$ - the goal of each campaign is determined by the project creator and usually cannot be changed after the start of the campaign.

- Financing level: $K_{p}$ - a series of observations measuring the share of investments received in relation to the campaign goal.

- Contribution: $K_{p}$ - individual contribution to the campaign as a share of the total capital goal.

- Campaign duration: $t^{\star}$ - the number of days after which the campaign is either successful of failed. 
- Campaign time passed: $t_{p}$ - a series of measures describing the share of time that has already passed in relation to the project duration for each of the data points in series $K_{p}$.

- Interest rate $r$.

- Investor endowment: $w_{i}$ - a large number of small investments are characteristic of crowdfunding campaigns. Each potential contributor is endowed a different amount depending on the mean monthly income in the region.

- Distance: $d_{i p}$ - the distance between the campaign creator and the potential contributor in kilometers.

- Nation: $n_{i p}$ - a Boolean variable that shows when the campaign creator and the potential investor live in the same country.

- Video budget: $v_{p}$ - reported project video budget in USD. The value is set to zero if the project does not feature a video.

- Project category $c_{p}$ - category identifier normalized to the 15 Kickstarter categories.

- Project location $l_{p}$ - location identifier (country city).

- Investment status $I_{i p}$ - Boolean variable indicating whether the investor has invested in the project in a previous period.

MODEL A

Potential investors consider as given project and investor parameters such as endowment, project goal, video budget, the capital funding level for the previous period, the share of the project duration that has passed up to that point, the distance between the investor and the project location and the country of both the investor and the founder. Investors control the amount they contribute to the project in the current period in order to maximize their utility for the period. Investor utility is approximated using the following three utility functions, each featuring a different level of investor learning (through artificial, or 'machine, learning):

$$
\begin{aligned}
\mathrm{A} 1: u_{i t}= & U\left(w_{i t}-k_{i p t}, d_{i p}, K^{\star}, v_{p}, n_{i p}, I_{i p}, K_{i p t-1}, t_{i p t-1}\right) \\
\mathrm{A} 2: u_{i t}= & U\left(w_{i t}-k_{i p t}, d_{i p}, K^{\star}, v_{p}, n_{i p}, I_{i p}, K_{i p t-1}, t_{i p t-1},\right. \\
& \left.K_{i p t-2}, t_{i p t-2}\right) \\
\mathrm{A} 3: u_{i t}= & U\left(w_{i t}-k_{i p t}, d_{i p}, K^{\star}, v_{p}, n_{i p}, I_{i p}, K_{i p t-1},\right. \\
& \left.t_{i p t-1}, K_{i p t-2}, t_{i p t-2}, K_{i p t-3}, t_{i p t-3}\right)
\end{aligned}
$$

Assumptions: 


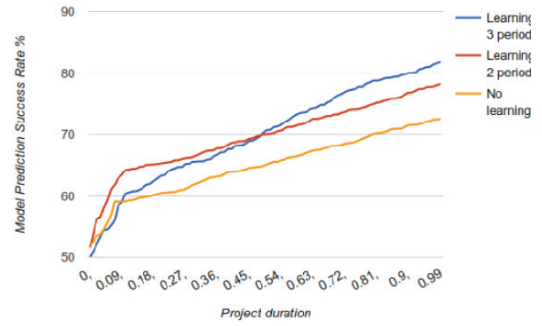

FIgURE 11 Model Prediction Accuracy for Eventually Successful Projects

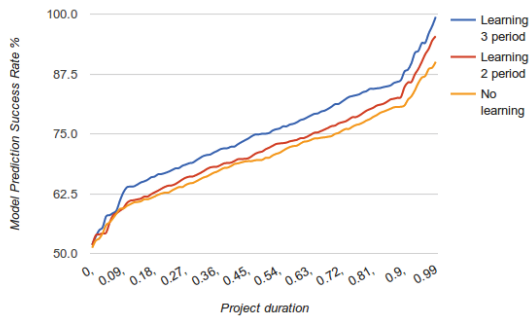

FIgURE 12 Model Prediction Accuracy for Eventually Unsuccessful Projects

- Individuals value the available income they have left after investment.

- Individuals are not risk neutral.

- Individuals are able to determine campaign risk factors such as founding team quality and project goal size.

- Individuals value the success rate of local campaigns higher than the success rate of distant projects.

- Individuals learn from the investment dynamics of the project up to that point.

In order to configure the parameters of the model $80 \%$ of the data was used for optimization and $20 \%$ for validation and testing. The model achieves an overall accuracy of $84 \%$ in predicting whether a project will manage to gather enough investments for all examined data points.

Figure 11 and figure 12 display the evolution of the models' predictions over project duration. Clearly the addition of learning which allows the model to consider the investments made in the previous few periods improves the rate of successful predictions at all stages of project duration.

The two areas of rapid prediction improvement in the beginning and in the end of projects show the impact of the temporal investment factors. These factors allow the model to rapidly increase its accuracy in the first stages of the project. They are relatively more significant for campaigns raising a higher amount in this initial period - thus on average successful project predictions experience a slightly bigger initial accuracy spike.

The model is relatively better at predicting the outcome of unsuccessful campaigns than it is at predicting the end result of projects that eventually turn out to be successful, as shown in figure 7 and figure 8 confirming the observation that failing campaigns are easier for investors to spot. 


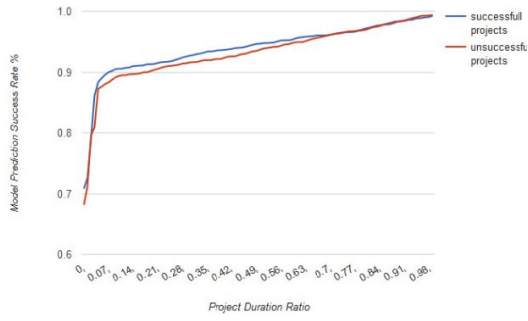

FIgURE 13 Model B Random Forest Prediction Accuracy

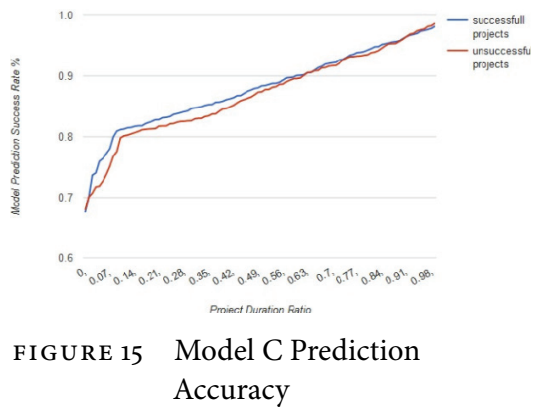

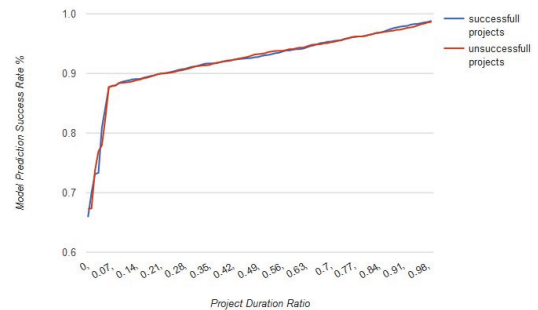

FIgURE 14 Model B Naive Bayes Prediction Accuracy

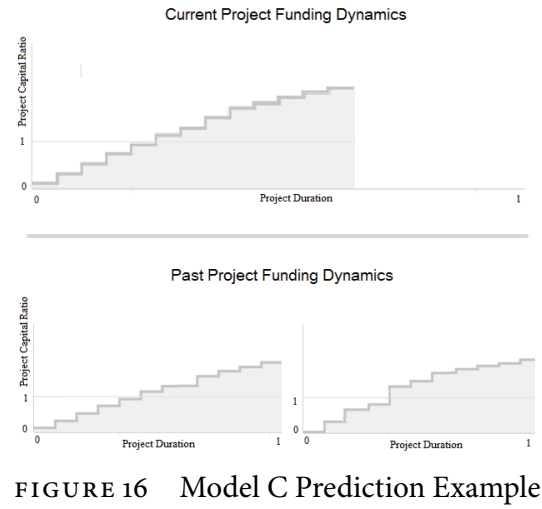

In line with the data observations projects exhibit a spike in investor activity near the end of project duration - the effect can be observed in the failed project predictions (figure 12). The same is not true for successful projects (figure 11) which have a steadily growing prediction rate after the first $10 \%$ of campaign duration.

MODEL B

Using all model variables two distinct machine learning classifiers were used to label projects as successful or unsuccessful. Naive Bayes and Random Forest classifiers were used, yielding similar results. The model averages 93\% accuracy among all projects and unlike Model A behaves symmetrically for failed and successful campaigns.

\section{MODEL C}

Using only the project category model variable, the investment ratio time series and the duration ratio time series a simple curve is constructed to represent the funding dynamics of all past and current projects. To 
predict the success of a currently active project its investment curve is compared to the curves of all projects in the same category and the least squares difference between all of them is computed. Afterwards the $\mathrm{N}$ closest matching previous projects in terms of funding dynamics are used to predict the end state of the currently active project.

The predictions of this simple model are strikingly accurate when a large number of past observations in the current category are available. Similarly to Model A the prediction success rate rapidly increases in the first $10 \%$ of campaign duration and experiences a gradual increase up to the $90 \%$ mark of project duration, when the growth rate of prediction success rate slightly rises. The model averages an $87 \%$ success rate in accurately predicting the end state of the campaign. Its prediction success rate is symmetric across successful and unsuccessful projects. The models' predictions are similar for projects in the final $95 \%$ of project duration compared to Model A. Model C is much more accurate than Model A in making predictions about campaigns that are in their early stages, which shows the importance of project category.

\section{Discussion, Limitations and Conclusions}

Crowdfunding has achieved exponential growth in the last few years and can be regarded as an alternative to traditional financial mediums available to entrepreneurs such as banks, venture capitalists and angel investors. The analysis of transaction level data in this paper could be used by both investors and entrepreneurs to achieve a more satisfying outcome of the crowdfunding process. Furthermore, the models can be employed by crowdfunding platforms to improve the efficiency of the matching process between investors and entrepreneurs. In particular, crowdfunding brings to consumers the ability to preorder desirable products that are not currently available in the market at the cost of taking the risk that that the project may not succeed or the founders may not manage to produce the investment reward after the crowdfunding campaign concludes. The present paper limits its analysis to the duration of the campaign, ignoring risks associated with project execution. The paper makes several observations that can be used by potential investors in order to make informed investments driven by their own risk aversion. Investors using the techniques that the paper proposes for characterizing project risk will be able to determine the probability of project success at all stages of project duration. This will allow them to make more knowledgeable decisions and investment trade-offs such as investing in products only offered to 
early investors versus having their capital locked up for the duration of the whole project, only to find out that the project failed and they will not receive the desired product.

As all three models demonstrate, investors can use the outcome of similar past campaigns whose status is already known to determine the probability of a currently active project not reaching its goal. A simple look of the funding dynamics of comparable projects is a good predictor of the end result as Model $\mathrm{C}$ has shown. A potential investor can use the funding ratio that the currently active project has achieved after $10 \%$ of project duration has passed and compare it with data for similar projects. A safer approach would be to track the growth rate after the $10 \%$ duration mark as in general it is relatively stable across all projects, to determine the likelihood of project success. In general, using the information that founders make available about their own experience and expectation in addition to the quality of their presentation can lead to more accurate forecasts of project risk.

On the other hand, project creators have control over the most important determinants of project success namely the capital goal, campaign duration and the quality of their own presentation to investors. Before starting a new crowdfunding venture, founders should analyse similar past campaigns past as if they were a potential investor. This will allow them to set realistic project parameters. The project updates and comments of previous crowdfunding ventures are a valuable source of information for founders which allows them to see what the concerns of investors are and what problems other founders have faced. After the campaign parameters have been chosen, founders must make sure that they provide adequate information about their own level of experience and plans for the future. Investors are more likely to contribute towards projects that are open about their structure and qualifications. Presentation is very important. Successful projects are shown to spend $5-10 \%$ of requested project goal on professional video production and copywriting.

Similarly, founders should continue to actively monitor the state of their crowdfunding project throughout its duration, providing regular updates and responding to investor comments. After $20 \%$ of project duration has passed they can use the data they have gathered about the funding dynamics of their own campaign to make an adjustment in the investment rewards in order to boost their chances of success. Overall, with the ever evolving technology provided by the crowdfunding platform, and the increase in data availability, the analysis that this paper provides 
can be streamlined, which could potentially allow investors to set their risk premium and receive recommendations about matching projects in their area of interest from the platform. This would increase public understanding of the crowdfunding market and allow efficient discussion, market matching and legislation to take place.

In conclusion, there exists a set of consistent dynamics that govern the development of the majority of crowdfunding ventures. Through analysis of transaction-level data as well as product and platform specifications this paper has shown that the development and even the eventual outcome of crowdfunding projects can be reliably determined at a very early stage. In particular, the models presented in this paper reach an average of $83 \%$ accuracy in predicting the outcome of a crowdfunding campaign at any point throughout its duration. Still, that leaves a lot of room for further improvement in terms of model's forecasting power, and leaves ample venues for future work in that area.

\section{References}

Agrawal, A. K., C. Catalini, and A. Goldfarb. 2011. 'The Geography of Crowdfunding.' NB ER Working Papers 16820, National Bureau of Economic Research, Cambridge, m A.

Allison, T. H., B. C. Davis, J. C. Short, and J. W. Webb. 2014. 'Crowdfunding in a Pro-Social Micro-Lending Environment: Examining the Role of Intrinsic versus Extrinsic Cues.' Entrepreneurship Theory and Practice 39 (1): 53-73.

Belleflamme, N., M. Omrani, and M. Peitz. 2015. 'The Economics of Crowdfunding Platforms.' CORE Discussion Paper 2015015, Universite catholique de Louvain, Ottignies-Louvain-la-Neuve.

Belleflamme, P. L., and T. Schwienbachner. 2011. 'Crowdfunding: Tapping the Right Crowd.' core Discussion Paper 2011032, Universite catholique de Louvain, Ottignies-Louvain-la-Neuve.

Burtch, G., A. Ghose, and S. Wattal. 2013. 'An Empirical Examination of the Antecedents and Consequences of Contribution Patterns in CrowdFunded Markets.' Information Systems Research 24 (3): 499-519.

Centre for Economic Policy Research, London.

Chen, N., A. Ghosh, and N. S. Lambert. 2014. 'Auctions for Social Lending: A Theoretical Analysis.' Games and Economic Behavior 86:367-91.

Cochrane, J. 2005. 'The Risk and Return of Venture Capital.' Journal of Financial Economics 75 (1): 3-52.

Cumming, D., and S. A. Johan. 2009. Venture Capital and Private Equity Contracting: An International Perspective. London: Academic Press. 
Elsner, D. 2013. 'Corporate Crowdfunding.' In Finanzdienstleister der nächsten Generation - Die neue digitale Macht der Kunden, edited by O. Everling, R. Lempka, and M. Müller, 401-22. Frankfurt am Main: Frankfurt-School-Verlag.

Everett, C. 2010. 'Group Membership, Relationship Banking and Loan Default Risk: The Case of Online Social Lending.' Banking and Finance Review 7 (2): 15-54.

Freedman, S., and G. Jin. 2014. 'The Signaling Value of Online Social Networks: Lessons from Peer-to-Peer Lending.' N B E R Working Paper 19820, National Bureau of Economic Research, Cambridge, MA.

Gerber, E., J. Hui, and P. Kuo. 2012. 'Crowdfunding: Why People Are Motivated to Post and Fund Projects on Crowdfunding Platforms.' https://www.researchgate.net/publication/261359489_Crowdfunding _Why_People_are_Motivated_to_Post_and_Fund_Projects_on _Crowdfunding_Platforms

Haas, P., I. Blohm, and J. Leimeister. 2014. 'An Empirical Taxonomy of Crowdfunding Intermediaries.' Paper presented at the International Conference on Information Systems (ICIS) 2014, Auckland, 14-17 December.

Hemer, J. 2011. 'A Snapshot on Crowdfunding.' Working Papers Firms and Regions R2/2011, Fraunhofer Institute for Systems and Innovation Research (ISI), Karlsruhe.

Herzenstein, M., and R. Andrews. 2008. 'The Democratization of Personal Consumer Loans? Determinants of Success in Online Peer-toPeer Lending Communities.' http://ssrn.com/abstract $=1147856$

Hildebrand, T., M. Puri, and J. Rocholl. 2013. 'Adverse Incentives in Crowdfunding.' http://ssrn.com/abstract $=1615483$

Iovino, F., and G. Migliaccio. 2016. 'E-Marketing by Energy Companies.' In 9th Annual Conference of the EuroMed Academy of Business: Innovation, Entrepreneurship and Digital Ecosystems, edited by D. Vrontis, Y. Weber, and E. Tsoukatos, 1034-46. Cyprus: Euromed Press.

_. (In press). 'Mobile Marketing and Strategy by Energy Companies.' International Journal Public Sector Performance Management.

Kim, K., and S. Viswanathan, S. 2013. 'The Experts in the Crowd: The Role of Reputable Investors in a Crowdfunding Market.' ss R N Working Paper 2258243, Social Science Research Network.

Koning, R., and J. Model. 2013. 'Experimental Study of Crowdfunding Cascades: When Nothing is Better than Something.' http://ssrn.com/ abstract $=2308161$

Kuppuswamy, V., and B. L. Bayus. 2013. 'Crowdfunding Creative Ideas: The Dynamics of Project Backers in Kickstarter' Research Paper 2013-15, UnC Kenan-Flagler Business School, Chapel Hill. 
Lin, Y., W. H. Boh, and K. H. Goh. 2014. 'How Different Are Crowdfunders?' http://ssrn.com/abstract=2397571

Lin, M., N. R. Prabhala, and S. Viswanathan. 2009. 'Social Networks as Signaling Mechanisms: Evidence from Online Peer-to-Peer Lending.' https://pdfs.semanticscholar.org/o1c5/ o7b28ec8e2f8a1382c4da4b75f31257715bo.pdf

Maeschle, O. 2012. 'Rationing of Excessive Demand on CrowdinvestingPlatforms.' Thünen - Series of Applied Economic Theory Working Papers 126, Leibniz Information Centre for Economics, Leibniz.

Mollick, E. 2013. 'Swept Away by the Crowd? Crowdfunding, Venture Capital, and the Selection of Entrepreneurs.' http://ssrn.com/abstract $=2239204$

- 2014. 'The Dynamics of Crowdfunding: An Exploratory Study' Journal of Business Venturing 29 (1): 1-16.

Ordanini, A., L. Miceli, M. Pizzetti, and A. Parasuraman. 2011. 'CrowdFunding: Transforming- Customers into Investors through Innovative Service Platforms.' Journal of Service Management 22 (4): 443-70.

World Bank. 2013. Crowdfunding Potential for the Developing World. Washington, DC: World Bank.

Viswanathan, S., M., and N. R. Prabhala. 2013. 'Judging Borrowers by the Company They Keep: Friendship Networks and Information Asymmetry in Online Peer-to-Peer Lending,' Management Science 59 (1): 1735 .

Wash, R., and J. Solomon. 2014. 'Coordinating Donors on Crowdfunding Websites.' In CSCW'14: Proceedings of the 17th ACM Conference on Computer Supported Cooperative Work \& Social Computing, 38-48. https://doi.org/10.1145/2531602.2531678

Zvilichovsky, D., Y. Inbar, and O. Barzilay. 2013. 'Playing Both Sides of the Market: Success Andreciprocity on Crowdfunding Platforms.' Paper presented at the International Conference on Information Systems, Milan, 15-18 December. 